\title{
Struktur Mikro dan Sifat Listrik Material Ferroelektrik Barium Titanat dengan doping Stronsium
}

\author{
Suwarni, ${ }^{1}$ Alpi Zaidah, ${ }^{1}$ Agus Supriyanto, ${ }^{2}$ Anif Jamaluddin, ${ }^{3}$ dan Yofentina Iriani ${ }^{2, *}$ \\ ${ }^{1}$ Jurusan Ilmu Fisika Program Pascasarjana, Universitas Sebelas Maret Surakarta \\ Jl. Ir. Sutami No.36 A Kentingan, Surakarta 57126 \\ ${ }^{2}$ Jurusan Fisika, Fakultas Matematika dan Ilmu Pengetahuan Alam, Universitas Sebelas Maret Surakarta \\ Jl. Ir. Sutami No.36 A Kentingan, Surakarta 57126 \\ ${ }^{3}$ Program Studi Fisika, Fakultas Keguruan dan Ilmu Pendidikan, Universitas Sebelas Maret Surakarta \\ Jl. Ir. Sutami No.36 A Kentingan, Surakarta 57126
}

Intisari

\begin{abstract}
Material ferroelektrik Barium Strontium Titanat $\left(\mathrm{Ba}_{x} \mathrm{Sr}_{1-x} \mathrm{TiO}_{3}\right.$, BST) dengan variasi doping mol Sr 0,01; 0,02 dan 0,03 telah dibuat menggunakan metode reaksi fasa padat. Sampel dicetak dalam bentuk bulk (padatan) kemudian di-sintering pada temperatur $900^{\circ} \mathrm{C}$ dengan holding time 2 jam. Karakterisasi sampel dilakukan menggunakan X-Ray Diffractometer (XRD) untuk mengetahui tingkat kekristalan dan ukuran kristal dari sampel. Pengujian RCL meter untuk mengetahui besarnya nilai konstanta dielektrik. Hasil karakterisasi XRD sampel memperoleh data dan diolah dalam bentuk grafik hubungan antara intensitas terhadap sudut 2 theta. Material BST dengan variasi doping mol Sr 0,01;0,02 dan 0,03 memiliki struktur kristal tetragonal, dengan parameter kisi $\operatorname{Sr} 0,01$ dan 0,03 adalah sama yaitu $\mathrm{a}=\mathrm{b}=3,996 \AA$ dan $\mathrm{c}=4,012 \AA$ sedangkan untuk $\operatorname{Sr} 0,02$ adalah $\mathrm{a}=\mathrm{b}=3,998 \AA$ dan $\mathrm{c}=4,022 \AA$. Ukuran kristal berturut-turut adalah $28,4 \mathrm{~nm} ; 32,3 \mathrm{~nm}$ dan $54,8 \mathrm{~nm}$. Semakin besar ukuran kristal, nilai rata-rata regangan kisi semakin kecil seiring dengan meningkatnya penambahan Sr. Pengukuran konstanta dielektrik (K) dilakukan pada rentang frekuensi $1 \mathrm{kHz}$ sampai $80 \mathrm{kHz}$ dan nilai tertinggi adalah pada $\mathrm{Sr} 0,03$ sebesar 18,55 .
\end{abstract}

\begin{abstract}
Barium Strontium Titanate ferroelectric material $\left(\mathrm{Ba}_{x} \mathrm{Sr}_{1-x} \mathrm{TiO}_{3}\right)$ with doping variation $\mathrm{Sr} 0.01 \mathrm{~mol} ; 0.02$ and 0.03 have been made using solid state reaction method. Samples printed in the form of bulk (solid) and then in-sintering at a temperature of $900^{\circ} \mathrm{C}$ with a holding time 2 hours. Characterization of samples was performed using X-Ray Diffractometer (XRD) to determine the level kekristalan and crystal size of the sample. RCL meter testing to determine the value of the dielectric constant. XRD characterization results of the samples obtained data and processed in the form of a graph of intensity against angle 2 theta. BST material with doping variation Sr $0.01 \mathrm{~mol} ; 0.02$ and 0.03 have a tetragonal crystal structure, in which the Sr lattice parameter of 0.01 and 0.03 are the same, namely $\mathrm{a}=\mathrm{b}=3.996 \AA$ and $\mathrm{c}=4.012 \AA$, while for $\mathrm{Sr} 0.02$ is $\mathrm{a}=\mathrm{b}=3.998 \AA$ and $\mathrm{c}=4.022 \AA$. Crystal size respectively adalah $28.4 \mathrm{~nm} ; 32.3 \mathrm{~nm}$ and $54.8 \mathrm{~nm}$. The larger the crystal size, the average value of the smaller lattice strain along with the increasing addition of Sr. Measurement of dielectric constant (K) performed in the frequency range $1 \mathrm{kHz}$ to $80 \mathrm{kHz}$ and the highest value was at $0.03 \mathrm{Sr}$ at 18.55 .
\end{abstract}

KATA KUNCI: Barium strontium titanate, solid state reaction, the lattice parameters, dielectric constant

\section{PENDAHULUAN}

Sifat khusus dari material ferroelektrik adalah sifat dielektrik, pieroelektrik dan piezoelektrik. Pemanfaatan material ferrolektrik dilakukan berdasarakan masing-masing sifat-sifat tersebut. Pada penelitian ini dilakukan pemanfaatan material ferroelektrik berdasarkan sifat dielektriknya. Material ferrolektrik dapat difabrikasi sesuai kebutuhan serta mudah diintegrasikan dalam bentuk divais. Aplikasi divais berdasarkan sifat histerisis dan konstanta dielektrik yang tinggi adalah pada memori Dynamic Random Access Memory (DRAM) [1].

*E-MAIL: yopen_2005@yahoo.com
Material ferroelektrik yang mempunyai perpaduan sifat paling menarik untuk aplikasi memori adalah Barium Stronsium Titanat. Material BST mempunyai konstanta dielektrik yang tinggi, loss dielektrik rendah, densitas kebocoran arus rendah. Konstanta dielektrik yang tinggi akan meningkatkan kapasitansi muatan lebih tinggi sehingga penyimpanan muatan juga lebih banyak [1].

Pembuatan BST dapat dilakukan beberapa cara diantaranya Metalorganic Chemical Vapor Deposition (MOCVD) [2], Pulsed Laser Deposition (PLD) [3], Magnetron Sputtering [4], serta Chemical Solution Deposition atau metode sol gel dan metode reaksi fasa padat (solid state reaction) [5].

$\mathrm{Ba}_{x} \mathrm{Sr}_{1-x} \mathrm{TiO}_{3}$ memiliki struktur kristal tetragonal dan bersifat ferroelektrik jika $x \geq 0,75$. Ketika $\mathrm{SrTiO}_{3}$ ditam bahkan pada $\mathrm{BaTiO}^{-3}$, ion $\mathrm{Sr}^{2+}$ akan menggantikan ion 
$\mathrm{Ba}^{2+}$. Penggantian $\mathrm{Ba}^{2+}$ oleh $\mathrm{Sr}^{2+}$ dapat mengubah sifatsifat listrik serta dapat digunakan untuk mengendalikan konstanta dielektrik dengan mengatur komposisi larutan padatan materialnya [6].

Penelitian mengenai $\mathrm{Ba}_{x} \mathrm{Sr}_{1-x} \mathrm{TiO}_{3}$ dengan $\mathrm{x}=0,90$ oleh Maharsi [7] didapatkan parameter kisi $\mathrm{a}=\mathrm{b}=3,986 \AA$ dan $\mathrm{c}=$ $3,988 \AA$ A. Nilai konstanta dielektrik maksimum diperoleh pada temperatur $900^{\circ} \mathrm{C}$ sebesar 3650 pada frekuensi minimum 0,01 kHz. Kemudian oleh Indriana (2014) $\mathrm{Ba}_{x} \mathrm{Sr}_{1-x} \mathrm{TiO}_{3}$ dengan $\mathrm{x}=0,95$ didapatkan nilai parameter kisi $\mathrm{a}=\mathrm{b}=3,988 \AA$ dan $\mathrm{c}=4,002 \AA$ dan nilai konstanta dielektrik sebesar 4420 juga pada frekuensi minimum $0,01 \mathrm{kHz}$ [8].

Nilai parameter kisi $\mathrm{Ba}_{x} \mathrm{Sr}_{1-x} \mathrm{TiO}_{3}$ dengan $\mathrm{x} \geq 0,75$ berdasarkan International Centre for Diffraction Data (ICCD) memiliki sistem kristal tetragonal dengan parameter kisi $\mathrm{a}=\mathrm{b}$ $=3,977 \AA$ dan $\mathrm{c}=3,988 \AA$ yakni $\mathrm{Ba}_{0,77} \mathrm{Sr}_{0,23} \mathrm{TiO}_{3}$ [9].

Pada paper ini, $\mathrm{Ba}_{x} \mathrm{Sr}_{1-x} \mathrm{TiO}_{3}$ dengan variasi mol $\mathrm{Sr}=0,03$ ; 0,$02 ; 0,01$ dengan temperatur $900^{\circ} \mathrm{C}$, holding time 2 jam dibuat menggunakan metode reaksi fasa padat. Metode ini relatif sederhana dengan mencampurkan semua bahan dasar kemudian dikompaksi (ditekan) dilanjutkan dengan proses sintering pada temperatur tertentu sehingga terbentuk senyawa baru yang diinginkan [10]. Penelitian ini adalah untuk mengetahui pengaruh variasi presentasi doping mol $\mathrm{Sr}$ terhadap struktur mikro material dan terhadap sifat listrik yakni besarnya nilai konstanta dielektrik dari $\mathrm{Ba}_{x} \mathrm{Sr}_{1-x} \mathrm{TiO}_{3}$.

\section{METODE PENELITIAN}

Metode reaksi fasa padat merupakan metode padatan, yakni tanpa melibatkan penggunaan larutan. Pembuatan $\mathrm{Ba}_{x} \mathrm{Sr}_{1-x} \mathrm{TiO}_{3}$ dengan metode reaksi fasa padat adalah mencampurkan seluruh bahan yaitu $\mathrm{BaCO}_{3}, \mathrm{SrCO}_{3}$ dan $\mathrm{TiO}_{2}$. Pencampuran dilakukan dengan menggerus bahan agar terbentuk campuran yang homogen. Serbuk $\mathrm{Ba}_{x} \mathrm{Sr}_{1-x} \mathrm{TiO}_{3}$ kemudian dicetak dalam bentuk bulk (padatan) menggunakan alat hydarulic press dan di-sintering pada temperatur $900^{\circ} \mathrm{C}$ selama 2 jam.

Peralatan karakterisasi $\mathrm{Ba}_{x} \mathrm{Sr}_{1-x} \mathrm{TiO}_{3}$ dilakukan menggunakan XRD Bruker D8 Advance dengan $\lambda_{c u}$ sebesar 1,54056 $\AA$ untuk mengetahui struktur kristal dan ukuran kristal dari sampel. Data yang diperoleh dari XRD adalah berupa intensitas dan sudut difraksi $2 \theta$, kemudian dicocokkan dengan data base International Center for Diffraction Data (ICDD) no \#440093 untuk BST $x \geq 0,75$. Diagram alir penelitian ditunjukkan pada Gambar 1 .

Konstanta dielektrik diperoleh dari Pers.(1) dan berdasarkan data yang terbaca pada alat RCL meter digital (LCR-800 Series Gwinstek) berupa kapasitansi (C) dan faktor dissipasi (D). d merupakan tebal sampel (m), A luas permukaan sampel $\left(\mathrm{m}^{2}\right)$ dan $\epsilon_{\circ}$ adalah permitivitas dielektrik $\left(8,85 \times 10^{-12}\right.$ Farad.m $\left.m^{-1}\right)$.

$$
K=\frac{C d}{\epsilon_{\circ} A}
$$

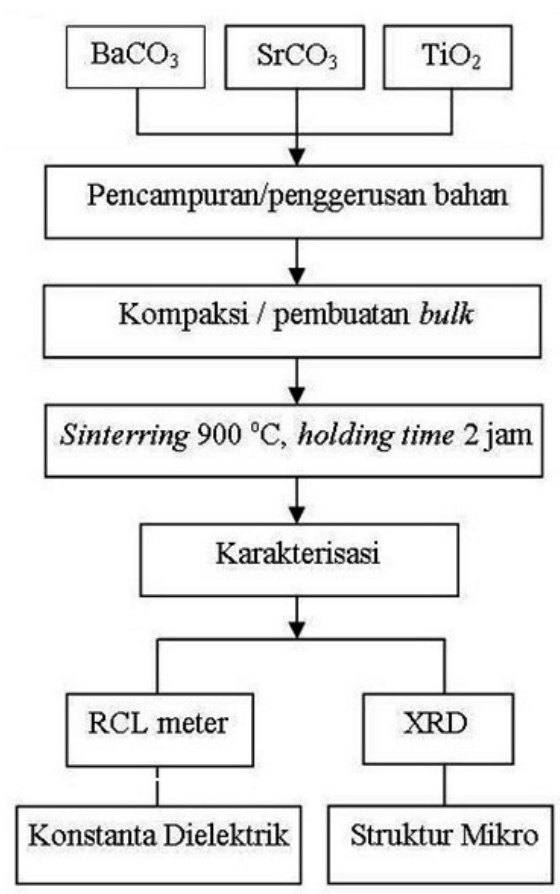

Gambar 1: Diagram alir penelitian.

\section{HASIL DAN PEMBAHASAN}

Pola difraksi yang diperoleh dari X-ray Diffractometer (XRD) digunakan untuk mengetahui parameter kisi, struktur kristal, ukuran kristal, regangan kisi serta tingkat kekristalan dari sampel. Gambar 2 menunjukkan pola difraksi yang terbentuk dari sampel $\mathrm{Ba}_{x} \mathrm{Sr}_{1-x} \mathrm{TiO}_{3}$ dengan variasi komposisi doping mol Sr 0,01;0,02;0,03 menggunakan temperatur sintering $900^{\circ} \mathrm{C}$ dengan holding time 2 jam.

Puncak-puncak dari pola difraksi yang dihasilkan oleh komposisi $\mathrm{Ba}_{x} \mathrm{Sr}_{1-x} \mathrm{TiO}_{3}$, variasi doping mol Sr 0,01;0,02 ; 0,03 dicocokkan dengan database ICDD \#440093. Dari pola difraksi yang telah dicocokkan dengan database terlihat bahwa masih terdapat serbuk $\mathrm{BaCO}_{3}$, hal ini dikarenakan dalam proses pencampuran masih ada bahan yang belum tercampur secara homogen.

Gambar 2 menunjukkan bahwa variasi komposisi mol Ba dan Sr menyebabkan pergeseran sudut difraksi $(2 \theta)$. Semakin besar komposisi mol Sr maka sudut difraksi akan semakin besar (bergeser ke kanan). Hal ini terkait dengan jari-jari atom $\mathrm{Sr}$ yang lebih kecil dari jari-jari atom Ba yaitu 1,12 Ådan 1,34 A. Perbedaaan jari-jari atom menyebabkan parameter kisi berbeda sehingga posisi atom juga akan berbeda, ketika sampel dikenai sinar-X maka puncak kristalnya juga akan berbeda.

Parameter kisi $\mathrm{Ba}_{x} \mathrm{Sr}_{1-x} \mathrm{TiO}_{3}$ dengan variasi komposisi mol $\mathrm{Ba}$ dan $\mathrm{Sr}$ diperoleh dari proses perhitungan. Parameter kisi $\mathrm{a}=\mathrm{b} \neq \mathrm{c}$ menunjukkan sampel BST mempunyai struktur kristal tetragonal. Tingkat ketetragonalan ditunjukkan dengan perbandingan nilai parameter kisi c dan a. Dapat dilihat bahwa semakin besar komposisi Sr, nilai tetragonality semakin be- 


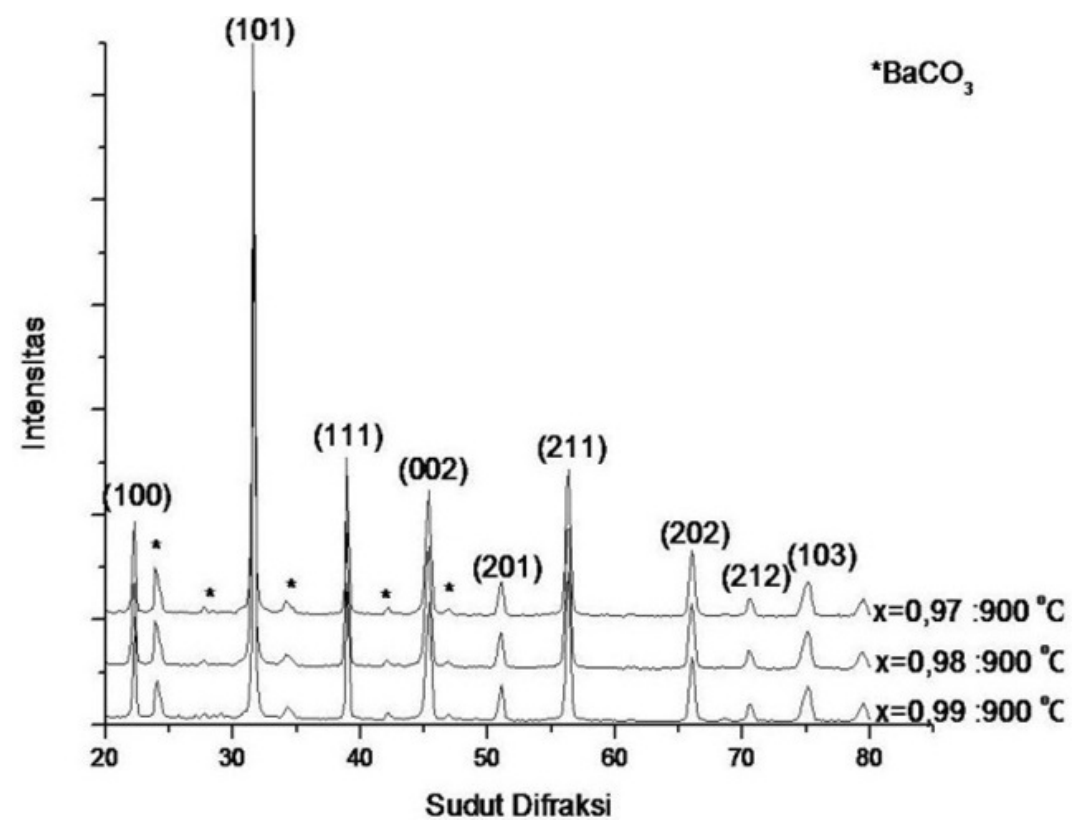

Gambar 2: Pola difraksi $\mathrm{Ba}_{x} \mathrm{Sr}_{1-x} \mathrm{TiO}_{3}$ temperatur $900^{\circ} \mathrm{C}$.

TABEL I: Parameter kisi dan Tetragonality $\mathrm{Ba}_{x} \mathrm{Sr}_{1-x} \mathrm{TiO}_{3}$.

\begin{tabular}{cccc}
\hline \hline Parameter Kisi & & $\mathrm{x}$ & \\
dan Tetragonality & 0,99 & 0,98 & 0,97 \\
\hline $\mathrm{a}=\mathrm{b}$ & 3,996 & 3,998 & 3,996 \\
$\mathrm{c}$ & 4,012 & 4,022 & 4,012 \\
$\mathrm{c} / \mathrm{a}$ & 1,004 & 1,006 & 1,004 \\
\hline \hline
\end{tabular}

sar, dapat dilihat pada $\mathrm{Sr} 0,01$ dengan $\mathrm{Sr} 0,02$, hal ini karena jari-jari $\mathrm{Ba}^{2+} 1,34 \AA$ lebih besar dibandingkan jari-jari $\mathrm{Sr}^{2+}$ $1,12 \AA$, ion $\mathrm{Sr}^{2+}$ menggantikan ion $\mathrm{Ba}^{2+}$, oleh sebab itu parameter kisinya semakin besar. Namun Pada Sr 0,01 dan 0,03 mempunyai parameter kisi yang sama, karena besarnya sudut difraksi yang terbentuk juga sama.

Tetragonality dari sampel BST untuk variasi komposisi doping mol Sr 0,01;0,02;0,03 memiliki tetragonality bernilai lebih dari 1 , karena $\mathrm{c}>\mathrm{a}$, ditunjukkan pada Tabel I.

Sudut difraksi yang diperoleh dari Gambar 2, digunakan untuk menghitung besarnya ukuran butir kristal dari grafik hubungan antara $\sin \theta$ dengan $\beta \cos \theta$ sehingga didapat grafik linier yang terdapat nilai ukuran butir kristal (D) yang dinya takan dalam nm dan regangan kisi $(\eta)$ yang dinyatakan dalam $\%$. Faktor-faktor yang mempengaruhi nilai FWHM ditunjukkan pada Persamaan Scherrer (2). Nilai $\beta$ merupakan nilai FWHM, $\theta$ adalah sudut difraksi, k adalah konstanta Scherrer (untuk struktur kristal tetragonal $=1$ ), dan $\lambda$ adalah panjang gelombang sinar-X yang digunakan.

$$
\beta=\frac{k \lambda}{D \cos \theta}
$$

Hubungan liniearitas antara $\sin \theta$ dengan $\beta \cos \theta$ ditunjukkan pada Pers.(3).

$$
\beta \cos \theta=\frac{k \lambda}{D}+c \sin \theta
$$

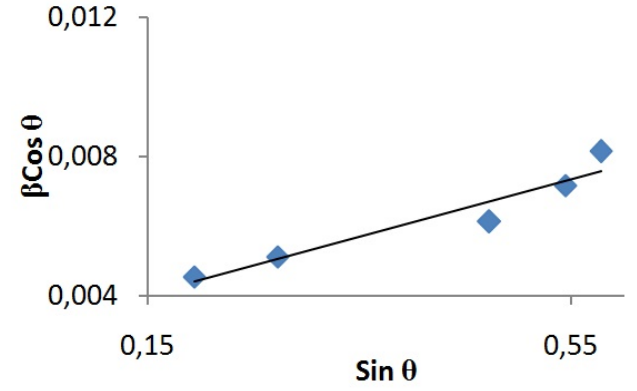

Gambar 3: Grafik plot $\cos \theta$ vs $\beta \cos \theta \mathrm{Ba}_{0,97} \mathrm{Sr}_{0,03} \mathrm{TiO}_{3}$.

TABEL II: Ukuran kristal $\mathrm{Ba}_{x} \mathrm{Sr}_{1-x} \mathrm{TiO}_{3}$.

\begin{tabular}{cc}
\hline \hline Sampel & $\begin{array}{c}\text { Ukuran Kristal } \\
\text { (nm) }\end{array}$ \\
\hline $\mathrm{Ba}_{0,99} \mathrm{Sr}_{0,01} \mathrm{TiO}_{3}$ & 28,4 \\
$\mathrm{Ba}_{0,98} \mathrm{Sr}_{0,02} \mathrm{TiO}_{3}$ & 32,3 \\
$\mathrm{Ba}_{0,97} \mathrm{Sr}_{0,03} \mathrm{TiO}_{3}$ & 54,8 \\
\hline \hline
\end{tabular}

Pengaruh variasi doping mol $\mathrm{Sr}$ terhadap ukuran kristal yaitu semakin besar penambahan Sr maka ukuran kristal juga semakin besar. Besarnya ukuran butir mempengaruhi jarak atom-atom dalam kristal yang semakin berdekatan sehingga menyebabkan regangan kisi juga semakin kecil. Besarnya ukuran kristal dan regangan kisi berdasarkan Pers.(3) ditunjukkan pada Tabel II.

Nilai regangan kisi menunjukkan perubahan panjang kisi. Gambar 3 menunjukkan persamaan linier $\mathrm{y}=0,008271674 \mathrm{x}$ $+0,00281168$ dan $\mathrm{R}^{2}=0,919606419$ untuk $\mathrm{Ba}_{0,97} \mathrm{Sr}_{0,03} \mathrm{TiO}_{3}$. Nilai regangan kisi berdasarkan persamaan tersebut adalah sebesar 0,8271\% dan ukuran partikel sebesar 54,8 nm. 


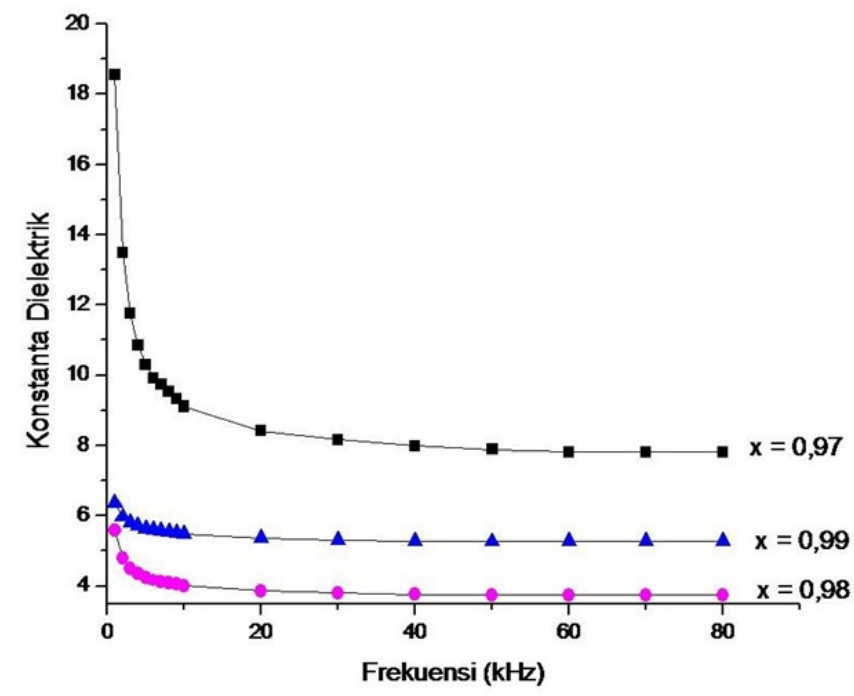

Gambar 4: Grafik hubungan frekuensi dengan konstanta dielektrik variasi doping mol Sr 0,01; 0,02; 0,03.

Besarnya nilai konstanta dielektrik yang diperoleh dari RCL meter adalah, bahwa semakin kecil frekuensi yang diberikan, nilai konstanta dielektrik yang dihasilkan semakin besar. Variasi nilai konstanta dielektrik yang diberikan adalah dari $1 \mathrm{kHz}$ sampai $80 \mathrm{kHz}$, dengan tegangan 1 volt. Besarnya nilai konstanta dielektrik bergantung besarnya nilai frekuensi yang diberikan, diitunjukkan pada Gambar 4.

Berdasarkan Gambar 4, dapat dilihat bahwa konstanta dielektrik maksimum sebesar 18,55 diperoleh pada frekuensi minimum $1 \mathrm{kHz}$ pada $\mathrm{Ba}_{0,97} \mathrm{Sr}_{0,03} \mathrm{TiO}_{2}$. Penambahan variasi mol Sr yang semakin besar mempengaruhi besarnya nilai kapasitansi sehingga konstanta dielektrik juga semakin besar karena struktur kristal juga semakin meningkat.

\section{SIMPULAN}

$\mathrm{Ba}_{x} \mathrm{Sr}_{1-x} \mathrm{TiO}_{3}$ yang telah dibuat menggunakan metode reaksi fasa padat, dapat disimpulkan bahwa pengaruh doping
Sr terhadap struktur kristal $\mathrm{Ba}_{x} \mathrm{Sr}_{1-x} \mathrm{TiO}_{3}$ adalah memperbesar sudut $2 \theta$ dan nilai parameter kisinya juga semakin besar. Besarnya nilai ukuran kristal juga dipengaruhi banyaknya penambahan mol Sr, semakin besar penambahan doping mol Sr ukuran kristal juga semakin besar yakni 54,8 nm sehingga konstanta dielektrik juga semakin besar yaitu pada frekuensi minimum sebesar 18,55 pada $1 \mathrm{kHz} \mathrm{Ba} \mathrm{Ba}_{0,97} \mathrm{Sr}_{0,03} \mathrm{TiO}_{2}$.

\section{Ucapan Terima Kasih}

Penulis mengucapkan terimakasih atas kerjasama dan dukungan dana melalui Hibah Pascasarjana DIPA PNBP UNS dengan nomor kontrak, No:501/UN27.11/PN/2014.
[1] K. Uchino, Ferroelectric Devices (Marcel Dekker, Inc. New York, 2000).

[2] T. Schneller, et al., J. Mater. Chem., 21, 7953 (2011).

[3] D. Pergolesi, et al., Nature Materials, 9, 846-852 (2010).

[4] T. Ohno, et al., Acta Chim. Slov., 61, 453-456 (2014).

[5] A. Ries, et al., Materials Characterization, 50, 217-221 (2003).

[6] M. M. Vijatovic, J.D. Bobic, and B.D. Stojanovic, Science of Sintering, 40, 235-244, (2008).

[7] R. Maharsi, Karaketrisasi Kekristalan dan Konstanta Dielektrik $\mathrm{Ba}_{0,9} \mathrm{Sr}_{0,1} \mathrm{TiO}_{3}$ yang Dibuat dengan Metode Solid State Reac- tion, Skripsi, Universitas Sebelas Maret, 2014.

[8] U. Indriana, Pengaruh variasi komposisi mol Barium (Ba) dan Strontium (Sr) terhadap sifat dielektriknya sebagai kapasitor atau penyimpan muatan pada $\mathrm{Ba}_{0,95} \mathrm{Sr}_{0.05} \mathrm{TiO}_{3}$, Skripsi, Universitas Sebelas Maret, 2014.

[9] F.H. Wee, et al., Progress In Electromagnetic Research, 121, 181-213 (2011).

[10] Pradhan, et al., Journal of Applied Physics, 97,093903 (2005). 